\title{
Analysis of Compliance with the Requirements for Geohod Actuating device Circuit Design for Soft Rocks Destruction
}

\author{
Vladimir Aksenov ${ }^{1,2}$, Valery Nesterov ${ }^{3}$, Vladimir Sadovets ${ }^{3}$, and Dmitry Pashkov, ${ }^{1, *}$ \\ ${ }^{1}$ Institute of Coal of the Federal Research Center Coal and Coal Chemistry Siberian Branch of the \\ RAS, 650610 Leningradsky av. 10, Kemerovo, Russia \\ ${ }^{2}$ Research Center "Siberian NPO", 650000 Sovetsky av., 56, Kemerovo, Russia \\ ${ }^{3}$ T.F. Gorbachev Kuzbass State Technical University, 650000 Vesennya st. 28, Kemerovo, Russia
}

\begin{abstract}
The article presents an analysis of circuit decisions of the actuating device of the geohod for the destruction of soft rocks for compliance with the requirements for them. To set the relevant goals and objectives of the study, the features of the work of a new class of mining machines (geohods) and the main provisions of geohod technology are presented. As a result of the study by the method of multicriteria analysis, it was found that the knife actuating device of the geohod meets the most complete requirements for the actuating device of the geohod. Requirements and options for circuit design for knife actuating device of geohods have been developed. To analyze the previously developed circuit design of the knife actuating device of the geohod, the method of multi-criteria analysis of decision making was chosen. Because of the analysis, four options for circuit design of knife actuating device of geohods were reasonably selected. The tasks for further research are formulated.
\end{abstract}

\section{Introduction}

Currently, the team of authors [1-6] is working on the development and creation of technical devices for a new class of mining equipment - geohods. These are machines that are designed for the sinking of underground workings for various purposes and their location in space [711]. It is proposed to call the technology for the formation of a cavity in the subterranean space, in which the main element is a geohod, a geohod technology.

According to the main provisions geohod technology, this machine is considered as an underground device that implements all the main stages of the technological cycle for the formation of a cavity in the underground space at the same time [12-14].

When substantiating the technical and constructive solutions of devices and elements of geohods, it is necessary to take into account the complex, helical movement of this mining machine to the bottom of the mine. In addition, the complex nature of the movement of the geohod creates the need to develop design models and obtain the dependences of the power and design parameters of the geohod, both with the external environment and with each other.

\footnotetext{
* Corresponding author: pashkov.d.a@inbox.ru
} 
One of the main elements of the geohod that affects the power parameters of this underground machine is its actuating device. In turn, the structural and power parameters of the actuating device are mathematically and functionally related to the structural parameters of the external mover of the geohod.

At the current stage of development of parameters of the geohod device, there are relevant tasks in substantiating the technical and constructive decisions of actuating device for the destruction of rocks of low hardness, as well as in developing methods for calculating and designing its elements. Therefore, the work aimed at substantiating the technical and constructive decisions of the actuating device for the destruction of low-strength rocks is relevant.

Based on the functional-and-constructive approach to the development of circuit and structural solutions for a new class of mining equipment $[2,4,6]$, as well as using the experience gained in creating new devices and elements of mining machines, we have developed more than 20 new variants of circuit design for a knife actuating device of geohod. The main of them are presented in Fig. 1.

The developed versions of the technical solutions of the knife actuating device correspond to the requirements imposed on the actuating device of geohods [2] and are intended for the destruction of soft rocks on the Protodyakonov scale, during the formation of a cavity in the underground space by a geohod.

To select a variant of the circuit solution of the knife actuating device of the geohod, which fully satisfies the developed requirements for this module of the mining machine, it is necessary to apply the methods of the mathematical apparatus. In our case, the most suitable is the method of multi-criteria analysis of decision making, known in the literature as MCDA [15-19].

Based on the comparison of the methods of multi-criteria analysis, we have identified the most suitable MCDA method for choosing the circuit solution of the IO geohod for the destruction of soft rocks. The highest compliance index was obtained by the TOPSIS method.

\section{Materials and Methods}

The initial data for making an informed choice of the circuit solutions of the knife actuating device of the geohod using the TOPSIS method is the decision matrix (Tab. 1), which includes evaluating alternatives according to criteria, as well as the weight of the criteria. The alternatives in this case are the options for circuit design of the knife actuating device of the geohod, and the requirements for them are the criteria.

Schematic solutions of knife actuating device of the geohod selected for analysis are presented in Fig. 1. The presented schematic solutions of knife actuating device of geohod allow obtaining the surface of the face of various shapes. To simplify the notation, each circuit solution is denoted by the index:

- a knife actuating device with a different number of cutting elements relative to the center of rotation of the geohod for destruction of soft rocks (Fig. 1, a), we assign the index AA1; - knife actuating device of the geohod with the geometry of the knife forming a flat bottom face (Fig. 1, b), we assign the index AA2;

- knife actuating device of the geohod with the geometry of the knife forming the bottom face of the inverse cone shape (Fig. 1, c), we assign the index AA3;

- knife actuating device of the geohod with the geometry of the knife forming the bottom of the shape of a convex cone (Fig. 1, d), assign the index AA4;

- knife actuating device of the geohod with the geometry of the knife forming the bottom of the shape of a convex ball (Fig. 1, e), assign the index AA5; 
a)

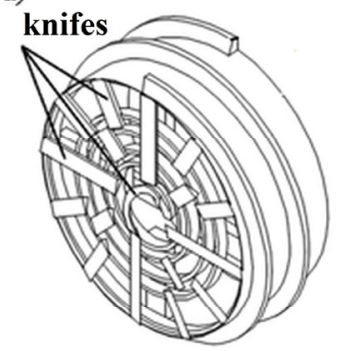

d)

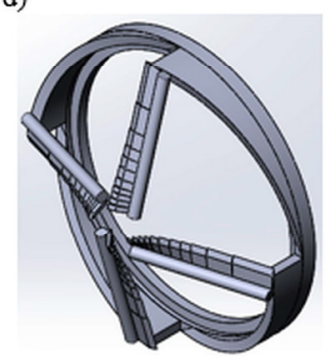

g) b)

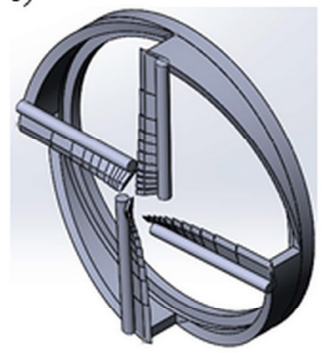

e)

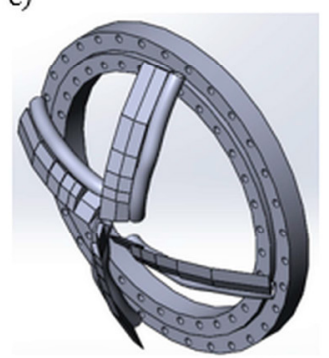

c)

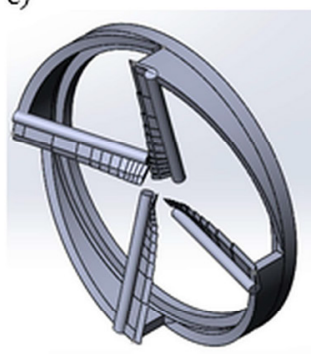

f)

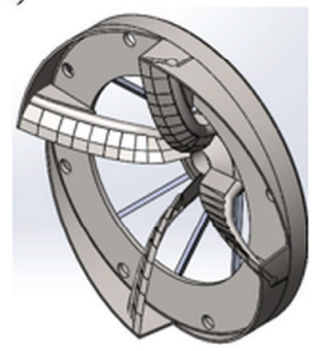

h)
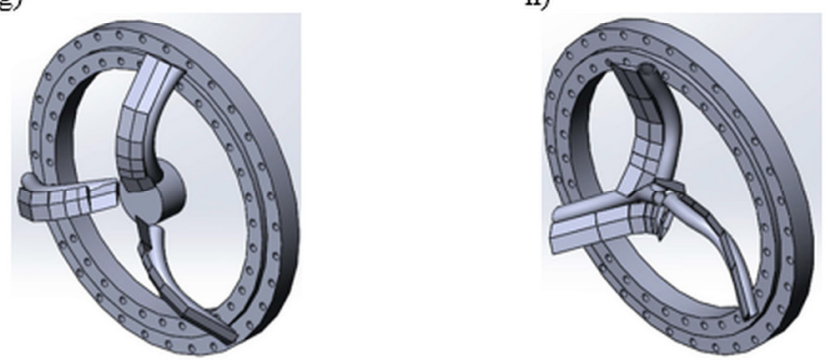

Fig. 1. Circuit design knife actuating device (AD) of the geohod: a) knife AD with a different number of cutting elements relative to the center of rotation of the geohod for the destruction of soft rocks; $b$ ) knife AD with the geometry of the knife, forming a flat shape of the face; c) knife AD of the geohod with the geometry of the knife, forming the face of the inverse cone; d) knife AD with the geometry of the knife, forming the bottom of the shape of a convex cone; e) knife AD of the geohod with the geometry of the knife forming a face of the shape of a convex ball; f) knife AD with the geometry of the knife, forming the bottom of the form with a concave radial-conical generatrix; g) knife AD with the geometry of the knife forming the face of the shape of a convex torus; h) knife AD of the geohod with the geometry of the knife, forming a face of the shape of a concave torus.

- knife actuating device of the geohod with the geometry of the knife forming the bottom of the mold with a concave radial-conical generatrix (Fig. 1, f), we assign the index AA6; - knife actuating device of the geohod with the geometry of the knife forming the bottom of the shape of a convex torus (Fig. 1, g), assign the index AA7;

- knife actuating device of the geohod with the geometry of the knife forming the bottom face of the concave torus shape (Fig. 1, h), assign the index AA8.

The full list of the above requirements to the actuating device of the geohod will not be taken into account, as for a number of requirements it is necessary to determine quantitative indicators. Therefore, for analysis, we accepted the requirements and gave them indices to simplify the input:

- provide sufficient maneuverability for any spatial location of the geohod (AB1);

- he possibility of continuous movement of the geohod to the face, including in unstable rocks (AB2); 
- retention of the weight of the broken rock and the possibility of feeding it to the loadingand-transporting systems when driving up (AB3);

- free access to the functional elements of the actuating device for repair, replacement and modification (AB4);

- work in strict accordance with the nature and parameters of the supply of the geohod to the face (AB5);

- compliance of the geometrical parameters of the geocode actuating device with the parameters of the propeller (AB6).

Table 1. Decision Matrix.

\begin{tabular}{|c|c|c|c|c|c|c|}
\hline \multirow{3}{*}{ Alternatives } & \multicolumn{7}{|c|}{ Criteria for evaluation } \\
\cline { 2 - 7 } & $\mathbf{A B 1}$ & $\mathbf{A B 2}$ & $\mathbf{A B 3}$ & $\mathbf{A B 4}$ & $\mathbf{A B 5}$ & AB6 \\
\cline { 2 - 7 } & \multicolumn{7}{|c|}{ Criterion weight $\boldsymbol{w i}$} \\
\cline { 2 - 7 } & 0.9 & 0.8 & 0.6 & 0.5 & 0.6 & 0.5 \\
\hline AA1 & 2 & 6 & 5 & 4 & 1 & 1 \\
\hline AA2 & 3 & 6 & 5 & 5 & 7 & 7 \\
\hline AA3 & 4 & 6 & 5 & 4 & 7 & 7 \\
\hline AA4 & 1 & 6 & 6 & 4 & 7 & 7 \\
\hline AA5 & 7 & 6 & 6 & 5 & 7 & 7 \\
\hline AA6 & 1 & 6 & 6 & 4 & 7 & 7 \\
\hline AA7 & 7 & 6 & 6 & 5 & 7 & 7 \\
\hline AA8 & 7 & 6 & 6 & 5 & 7 & 7 \\
\hline
\end{tabular}

Estimates of alternatives by criteria are normalized in order to be able to compare different systems of units. For this, the method of ideal normalization is used.

Ideal normalization requires dividing each estimate by the largest in each column.

The calculated values of $r_{a i}$ are summarized in Tab. 2 .

Next, weighted normalized coefficients are determined.

The calculated values of $v_{a i}$ are represented by the weighted normalized decision matrix (Tab. 3).

Table 2. $r_{a i}$ values at ideal normalization.

\begin{tabular}{|c|c|c|c|c|c|c|}
\hline \multirow{2}{*}{ Alternatives } & \multicolumn{7}{|c|}{$\boldsymbol{r}_{\boldsymbol{a} i}$} \\
\cline { 2 - 7 } & $\mathbf{A B 1}$ & $\mathbf{A B 2}$ & $\mathbf{A B 3}$ & $\mathbf{A B 4}$ & $\mathbf{A B 5}$ & $\mathbf{A B 6}$ \\
\hline AA1 & 0.285 & 1 & 0.833 & 0.8 & 0.143 & 0.143 \\
\hline AA2 & 0.429 & 1 & 0.833 & 1 & 1 & 1 \\
\hline AA3 & 0.571 & 1 & 0.833 & 0.8 & 1 & 1 \\
\hline AA4 & 0.143 & 1 & 1 & 0.8 & 1 & 1 \\
\hline AA5 & 1 & 1 & 1 & 1 & 1 & 1 \\
\hline AA6 & 0.143 & 1 & 1 & 0.8 & 1 & 1 \\
\hline AA7 & 1 & 1 & 1 & 1 & 1 & 1 \\
\hline AA8 & 1 & 1 & 1 & 1 & 1 & 1 \\
\hline
\end{tabular}

Normalized weighting coefficients are used to compare $v_{a i}$ with the largest $\left(v_{i}+\right)$ and smallest $\left(v_{i}-\right)$ coefficient selected for each criterion in Table 3. 
Table 3. Weighted normalized decision matrix.

\begin{tabular}{|c|c|c|c|c|c|c|}
\hline \multirow{2}{*}{ Alternatives } & \multicolumn{7}{|c|}{$\boldsymbol{v}_{\boldsymbol{a} i \boldsymbol{i}}$} \\
\cline { 2 - 7 } & $\mathbf{A B 1}$ & $\mathbf{A B 2}$ & $\mathbf{A B 3}$ & $\mathbf{A B 4}$ & $\mathbf{A B 5}$ & $\mathbf{A B 6}$ \\
\hline AA1 & 0.257 & 0.8 & 0.5 & 0.4 & 0.086 & 0.072 \\
\hline AA2 & 0.386 & 0.8 & 0.5 & 0.5 & 0.6 & 0.5 \\
\hline AA3 & 0.514 & 0.8 & 0.5 & 0.4 & 0.6 & 0.5 \\
\hline AA4 & 0.129 & 0.8 & 0.6 & 0.4 & 0.6 & 0.5 \\
\hline AA5 & 0.9 & 0.8 & 0.6 & 0.5 & 0.6 & 0.5 \\
\hline AA6 & 0.129 & 0.8 & 0.6 & 0.4 & 0.6 & 0.5 \\
\hline AA7 & 0.9 & 0.8 & 0.6 & 0.5 & 0.6 & 0.5 \\
\hline AA8 & 0.9 & 0.8 & 0.6 & 0.5 & 0.6 & 0.5 \\
\hline
\end{tabular}

The matrix of coefficients $v_{i}+$ and $v_{i}$-is presented in Tab. 4 .

\section{Results and Discussion}

We determine the proximity of each weighted normalized coefficient $v_{a i}$ (Tab. 3) to the largest and smallest coefficients.

Table 4. Matrix of the largest and smallest coefficients.

\begin{tabular}{|c|c|c|c|c|c|c|}
\hline \multirow{3}{*}{ Coefficients } & \multicolumn{6}{|c|}{ Criteria for evaluation } \\
\cline { 2 - 7 } & $\mathbf{A B 1}$ & $\mathbf{A B 2}$ & $\mathbf{A B 3}$ & $\mathbf{A B 4}$ & $\mathbf{A B 5}$ & \multirow{2}{*}{ AB6 } \\
& & & & & & \\
\hline$v^{+}$ & 0.9 & 0.8 & 0.6 & 0.5 & 0.6 & 0.5 \\
\hline$v^{-}$ & 0.129 & 0.8 & 0.5 & 0.4 & 0.086 & 0.072 \\
\hline
\end{tabular}

The calculated data are shown in Tab. 5 .

The final coefficient for choosing the circuit design of the actuating device of the geohod for the destruction of soft rocks is the relative coefficient of proximity to the ideal.

Relative approximation coefficients are recorded in Tab. 5.

Table 5. Proximity of indicators.

\begin{tabular}{|c|c|c|c|c|c|c|c|c|}
\hline & AB1 & AB2 & AB3 & AB4 & AB5 & AB6 & AB1 & AB2 \\
\hline$d_{a}^{+}$ & 0.939 & 0.524 & 0.411 & 0.778 & 0 & 0.778 & 0 & 0 \\
\hline$d_{a}^{-}$ & 0.128 & 0.724 & 0.772 & 0.677 & 1.0 & 0.677 & 1.0 & 1.0 \\
\hline $\mathrm{C}_{a}$ & 0.120 & 0.580 & 0.652 & 0.465 & 1.0 & 0.465 & 1.0 & 1.0 \\
\hline
\end{tabular}

Based on the subjectivity of introducing alternative assessments by criteria, at this stage it is impossible to determine the best version of the actuating device, but it makes sense to exclude from the further consideration the worst options under the indices AA1, AA2, AA4, AA6.

According to the results of the analysis, the following circuit options fully satisfy the requirements for actuating device of the geohod for the destruction of soft rocks:

- knife actuating device of the geohod with the geometry of the knife forming the bottom of the inverse cone shape (Fig. 1, c) (AA3);

- knife actuating device of the geohod with the geometry of the knife forming the bottom of the shape of a convex ball (Fig. 1, e) (AA5);

- knife actuating device of the geohod with the geometry of the knife forming the bottom of the shape of a convex torus (Fig. 1, g) (AA7); 
- knife actuating device of the geohod with the geometry of the knife forming the bottom face of the concave torus shape (Fig. 1, h) (AA8).

\section{Conclusion}

1. A decision matrix has been compiled (Tab. 1), which includes estimates of alternatives by criteria, as well as the weight of the criteria. Alternatives in this case are the options for circuit design of the actuating device of the geohod, and the criteria are the requirements for them. 2. To simplify the project, each circuit design of the actuating device of the geohod and the requirement are assigned indices.

3. By the method of multi-criteria analysis it has been established that the following circuit design meet the most fully presented requirements:

- knife actuating device of the geohod with the geometry of the knife forming the bottom face of the inverse cone shape;

- knife actuating device of the geohod with the geometry of the knife forming a face of the shape of a convex ball;

- knife $\mathrm{AD}$ of the geohod with the geometry of the knife, forming a face of the shape of a convex torus;

- knife actuating device of the geohod with the geometry of the knife forming the bottom face of the shape of a concave torus.

4. For reasonably selected circuit design for a knife actuating device of the geohod, it is necessary to develop a model for the interaction of elements of the actuating device with the geomedium and with devices and elements of the geohod.

\section{References}

1. A. A. Khoreshok, L. E. Mametev, A. Yu. Borisov, A. V. Vorobev, Applied Mechanics and Materials, 770, 434-438 (2015)

2. V. Aksenov, V. Sadovets, D. Pashkov, E3S Web Conf., 21, 03008 (2017)

3. A. Khoreshok, L. Mametyev, A. Borisov, A. Vorobiev, Stress-deformed state knots fastening of a disk tool on the crowns of roadheaders. Mining 2014. Taishan academic forum-project on mine disaster prevention and control. Chinese coal in the XXI century: Mining, green and safety. - Qingdao, China, October 17-20, 2014 (Atlantis press, Amsterdam-Paris-Beijing, 2014)

4. V. Aksenov, V. Sadovets, E. Rezanova, D. Pashkov, E3S Web Conf., 15, 03015 (2017)

5. A. A. Khoreshok, L. E. Mametev, A. Yu. Borisov, A. V. Vorobev, Applied Mechanics and Materials, 770, 429-433 (2015)

6. V. Aksenov, V. Sadovets, D. Pashkov, E3S Web Conf., 41, 03002 (2018)

7. V. V. Aksenov, A. B. Efremenkov, V. Y. Sadovets, D. A. Pashkov, IOP Conference Series: Materials Science and Engineering, 441, 012002 (2018)

8. S. Nishi, T. Seiki, Mem. Sch. Eng. Nagoya Univ., 1, 34 (1997)

9. B. Maidl, L. Schmid, W. Ritz, M. Herrenknecht, Hardrock Tunnel Boring Machines (Ernst\&Sohn, Berlin, 2008)

10. T. Wighman, ENR, 4, 9 (1998)

11. G. Brierley, Subsurface Excavation, 9, 28 (1998)

12. J. Carmody, R. Sterling. Undergroundspace design (Reinhold, New York, 1993) 
13. A. B. Efremenkov, $6^{\text {th }}$ International Forumon Strategic Technology (IFOST-2011) 2:1, 348 (2011).

14. A. A. Kazantsev, V. P. Kosykh, A. F. Revuzhenko, IOP Conference Series: Materials Science and Engineering, 91, 012089 (2015)

15. M. Y. Blashchuk, A. A. Kazantsev, R. V. Chernukhin, Appl. Mech. Mater., 682, 418 (2014)

16. G. H. Tzeng, Multiple Attribute Decision Making: Methods and Applications (Chapman and Hall, Boca Raton, 2011)

17. C. Zopounidis, Handbook of Multicriteria Analysis (Springer Berlin Heidelberg, Berlin)

18. S. Xiaoqian, Multiple Criteria Decision Analysis Techniques in Aircraft Design and Evaluation Processes (Technischen Universitat Hamburg, Hamburg, 2012)

19. A. Ishizaka, P. Nemery, Multi-criteria decision analysis: methods and software (John Wiley \& Sons, London, 2013) 